\title{
PHYSICOCHEMICAL CHARACTERISTICS, PESTICIDE RESIDUE AND AFLATOXIN CONTAMINATION OF COLD PRESSED PUMPKIN SEED (Cucurbita pepo L.) OILS FROM CENTRAL ANATOLIA REGION OF TURKEY
}

\author{
Fatma Nur ARSLAN ${ }^{1, *}$, Gönül AKIN ${ }^{1}$, İbrahim YILMAZ ${ }^{1}$ \\ ${ }^{1}$ Department of Chemistry, Faculty of Science, University of Karamanoğlu Mehmetbey, Karaman, Turkey
}

\begin{abstract}
In this study, physicochemical characteristics, pesticide residues and aflatoxin contaminations of cold pressed pumpkin seed (Cucurbita pepo L.) oils cultivated in four different central Anatolia regions of Turkey, were investigated. Lab-scale screw press machine was used to produce cold pressed pumpkin seed oils and the oil contents were found between $42.8 \%-47.4 \%$ for naked seeds. The physicochemical characteristic (refractive index, viscosity, color value, triglyceride profile analysis, peroxide value, iodine value, free fatty acid, saponification number, unsaponified matter, specific extinction values at 232 and $270 \mathrm{~nm}$ ) of cold pressed oils were determined by using different analytical techniques. The results showed that there was a nonsignificant difference between cold pressed pumpkin seed oils from different regions, in terms of physicochemical characteristics. The contents of pesticide residue and aflatoxin $B_{1}, B_{2}, G_{1}$ and $G_{2}$ contamination were determined by using validated UHPLC-MS/MS method. The chlorpyrifos pesticide residue was detected under the limit value declared by official authorities for the quality assessment of edible oils. Aflatoxins weren't detected in any of studied pumpkin seed oils. Therefore, the study provides important data for the cold pressed pumpkinseed oils, and proves that screw-pressed pumpkinseed oils are high quality, nutritious and valuable oils with higher levels of consumer acceptability.
\end{abstract}

Keywords: Cucurbita pepo L., Cold pressed oil, Physicochemical characteristic, UHPLC-MS/MS

\section{INTRODUCTION}

Pumpkins (Cucurbita spp.) are familiar plants widely cultivated and used as foodstuff since ancient times. A wide variety of Cucurbita species are cultivated in mild and subtropical regions, with the studied species being C. pepo, C. moschata, C. maxima, and C. mixta[1]. Among these species, Cucurbita pepo L. is an economically important member of Cucurbitaceae familyand among the ten leading vegetable crops worldwide with an annual product growing in temperate and subtropical regions [2]. For many years, the Cucurbita pepo L. seeds have been commonly used in the food industry, are utilized in the pharmaceutical and alternative medicine applications but also in the production of cold pressed pumpkin seed oil (PSO) [3, 4].

Cold pressed PSO is mostly obtained by pressing of untreated-dried, naked (hull-less) pumpkin seeds, with continuous mechanical screw-presses and outlet oil temperature below $50^{\circ} \mathrm{C}$ [5]. During screwpresses, neither the untreated oily seed nor the outlet oil is exposed to higher temperatures and chemical application consistent with the Codex Alimentarius and legislations for cold pressed oils [6,7]. The screw-processing technology of cold pressed PSO is performed by the following applications: harvesting, washing and drying to residual moisture content, and then storing of the pumpkin seeds. Before the screw-processing, the seeds pass throughout the magnetic cleaner, followed by elimination of organic impurities. The clean dried oily seeds are continuously reinforced to the screw-press and squeezed oil is then collected in dark-brown glass bottles. Undesired turbid matters in oil are removed by sedimentation or filtration, and then filtered oil is filled into dark glass bottles. Due to this traditional screw-process, the cold pressed PSOs maintain their natural composition with regard to the bioactive 
constituents and flavour. The main argument for the advantages of these oils is that during oil extraction, bioactive compounds present in the seed do not deteriorate due to the low processing temperatures. Thus, the consumption of cold pressed pumpkin seed oils is currently increasing [5].

Cold pressed PSO is an extraordinarily rich source of various bioactive compounds having functional properties used as edible oil or a potential nutraceutical. PSO belongs to the group of oils of high nutritive value due to its favourable bioactive compounds which have certain positive effects on the human health. Several health benefits from its regular dietary intake have been also reported, including cancer prevention, anti-inflammation, anti-diabetic and lowering of cholesterolemia [4, 8-10]. Besides the nutritive-pharmacological properties, there are several studies on PSOs that are characterized by their specific physicochemical properties which are considerably different from other kind of oils [5, 11]. Rabrenovic et al. (2014) evaluated the most important bioactive compounds of cold pressed oils from different pumpkin (Cucurbita pepoL.) seeds, and reported that the total tocopherol content ranged from $38.03 \pm 0.25$ to $64.11 \pm 0.07 \mathrm{mg} / 100 \mathrm{~g}$ of oil and physterol content ranged from $718.1 \pm 6.1$ to $897.8 \pm 6.8 \mathrm{mg} / 100 \mathrm{~g}$ of oil [5]. In addition to tocopherols, pumpkin seed oil (Cucurbita pepoL.) has a simple fatty acid profile with the dominant fatty acid being the nutritionally linoleic acid (35.6-60.8\%), as well as palmitic (9.5-14.5\%), stearic (3.1-7.4\%) and oleic acids (21.0-46.9\%) [12, 13]. Andjelkovic et al. (2010) also reported that the total polyphenol content in PSOs ranged from 25 to $51 \mathrm{mg} / \mathrm{kg}$ as gallic acid equivalents (GAEs) [12].

The researchers also reported that the content and amount of these bioactive compounds are differing among the varieties, dependent on climate and cultivation conditions. So, investigation of the bioactive contents of cold pressed oils from different varieties is very important to define the quality and shelf life of products. These quality parameters are also requested for labelling by the market [13]. The determination of the stability and physicochemical characteristics is a very sensitive issue; hence, studies on the cold pressed PSOs from different regions highlighted its richness in bioactive compounds and its physicochemical characteristics in respect to the edible oil quality. To our best knowledge, no data is available on the quality of pumpkin seed (Cucurbita pepo L.) oils cultivated in central Anatolia regions in detail and no investigation has been focused on the contamination of pesticide and aflatoxin in PSO by UHPLC-MS/MS technique. Therefore, this study was aimed (i) to determine the basic physicochemical characteristic (refractive index, viscosity, color value, triglyceride profile analysis, peroxide value, iodine value, free fatty acid, saponification number, unsaponified matter, specific extinction values at $232 \mathrm{~nm}$ and $270 \mathrm{~nm}$ ) by using different analytical techniques and (ii) to determine the contents of pesticide and aflatoxin contamination by using validated UHPLC-MS/MS techniques, for cold pressed pumpkin (Cucurbita pepo L.) oils cultivated in four different central Anatolia regions of Turkey. The findings of present study are expected to increase the knowledge on the characteristics of these valuable edible oils and provide as valuable contributions to better assess their potential as a source of functional edible oils in the industry.

\section{EXPERIMENTAL SECTION}

\subsection{Chemicals and Reagents}

All chemicals, reagents and solvents used were of analytical and HPLC grade and obtained from VWR International (Poole, UK), Sigma-Aldrich (St. Louis, USA) and Merck (Darmstadt, Germany). Deionised water (>18 M $\Omega . \mathrm{cm}$ ) was obtained from a Milli-Q system (Millipore, Brussels, Belgium) in our laboratory. Dispersive-solid phase extraction (SPE) sorbents for cleanup process included primary secondary amine (PSA) were obtained from Varian (Harbor City, CA, USA). The AflaTestP ${ }^{\circledR}$ immunoaffinity SPE cartridge columns were obtained from Sigma-Aldrich (St. Louis, USA). The blank pumpkinseed oil was obtained from Sigma-Aldrich (St. Louis, USA) certified organic (NOP) 
Higher purity pesticide standards (95\% or higher purity) were obtained from Wako (Osaka, Japan), Chemservice (West Chester, PA, USA), Sigma-Aldrich (St. Louis, USA) and Dr. Ehrenstorfer (Augsburg, Germany). Pesticide stock solutions were prepared in methanol at a concentration of $1000-2500 \mu \mathrm{g} . \mathrm{kg}^{-1}$ (ppb). The individual stock solutions were diluted with methanol to prepare mixed stock solutions for UHPLC-MS/MS analysis containing: carbaryl, chlorpyrifos, dimethoate, diuron, malathion, methidathion, omethoate, phosmet and simazine at a concentration of $1-50 \mu \mathrm{g} \cdot \mathrm{kg}^{-1}, 10-250$

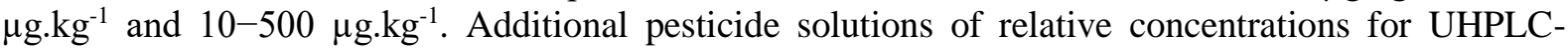
MS/MS were diluted appropriately from these stock solutions and all solutions were stored at $-20^{\circ} \mathrm{C}$ before analyses. Identification of pesticides were based on the criteria specified in commission decision 2002/657/EC [14];(i) the $t_{\mathrm{R}}$ of the analytes in the extract should correspond to that of the calibration standard (ii) the occurrence of three identification points, precursor ion and two fragments (iii) the relative ion intensities had to match with the permitted tolerances. Quantification of pesticides was based on peak areas. The aflatoxin mix analytical standard, in methanol (AF-B ${ }_{1}, A F-B_{2}, A F-G_{1}$ and AF-G was purchased from Sigma-Aldrich (St. Louis, USA). Pure triglycerides as standards including LLnLn, LLLn, LLL, OLLn, PLLn, OLL, PLL, LnPO, OOL, POL, StLL, PPL, OOO, StOL and PLSt were purchased from Sigma-Aldrich (St. Louis, USA) [triglyceride abbreviations are used in this study: P, palmitic acid (C16:0); St, stearic acid (C18:0); O, oleic acid (C18:1, $\left.\Delta^{9}\right)$; L, linoleic acid $\left(\mathrm{C} 18: 2, \Delta^{9,12}\right)$ and $\mathrm{Ln}$, linolenic acid $\left.\left(\mathrm{C} 18: 3, \Delta^{9,12,15}\right)\right]$.

\subsection{Cold Pressed Pumpkin Seed Oil Production By Screw-Pressing}

Four commercially available pumpkin seeds (Cucurbita pepo L.) were harvested in region of Celtik/Konya, Cumra/Konya, Iceri Cumra/Konya and Polatli/Ankara, central Anatolia regions of Turkey. Naked pumpkin seeds were of domestic origin and harvested in mid autumn of 2015, were purchased from local suppliers for laboratory-scale screw-pressing process. To determine the moisture and oil contents of pumpkin seeds, ISO-665 [15] and ISO-734-1[16] standard methods were used, respectively.

A lab-scale screw press machine (15 kg seed. $\mathrm{h}^{-1}$ capacity, single head, $2 \mathrm{hp}, 1.5 \mathrm{kw}$ power) in our laboratory was used for pressing of pumpkin seed samples. $40 \mathrm{rpm}$ screw rotation speed and $40^{\circ} \mathrm{C}$ temperatures were selected as process parameters. During the screw-pressing process, the temperature -did not exceed $40^{\circ} \mathrm{C}$ to prevent an increase of the content of oxidation products. The naked pumpkin seeds for screw-pressing were used as follows: Celtik region $(10 \mathrm{~kg})$, Cumra region $(7 \mathrm{~kg})$, Iceri Cumra region $(10 \mathrm{~kg})$ and Polatl region $(8 \mathrm{~kg})$. Following each set, oil and meal with oily cake were collected and weighed, and the oil was filtered to remove suspended materials. The cold pressed oils were centrifuged in a refrigerated centrifuge system (Sigma $2-16 \mathrm{~K}$, Germany) for $20 \mathrm{~min}$ at $10^{\circ} \mathrm{C}$. The oil phases were separated, weighed, flushed with inert gas and packed into dark-green glass bottles closed with screw caps, at the ambient temperature until analysis.

\subsection{Determination of Physical Characteristics}

The color values of cold-pressed oils were directly determined by a Lovibond tintometer (Model-F, Tintometer Ltd., Salisbury, U.K.) and were expressed as Lovibond units (LU). The color values were determined by using Cc 13e-92 AOCS official method [17] and expressed in yellow (Y), and red (R) units. Refractive index (RI) values were determined using Abbe Refactometer (Model NAR-3 T, ATAGO Co., Ltd., Tokyo, Japan) at a temperature of $25^{\circ} \mathrm{C}$. The viscosities of cold-pressed oils were determined by Brookfield viscometer (Brookfield Eng. Lab. Inc., USA). Of the PSO, $1 \mathrm{~mL}$ was placed on the plate of the viscometer with a LV-SC4-18 spindle and maintained at $40^{\circ} \mathrm{C}$ by a circulating water bath. 


\subsection{Determination of Chemical Characteristics}

The free fatty acid (FFA) content, peroxide value (PV), iodine value (IV), saponification value (SV) and unsaponified matter (USM) content of seed oils were determined according to Ca 5a-40, Cd 8b-90, Cd 1-25, Cd 3c-91 and Ca 6a-40 AOCS official methods [17], respectively. Conjugated dien and trien contents of seed oils were determined by measuring the specific extinction coefficients $\left(\mathrm{K}_{232}\right.$ and $\left.\mathrm{K}_{270}\right)$ as well as their relation or $R$-values $\left(\mathrm{K}_{232} / \mathrm{K}_{270}\right)$, according to the AOCS method [17]. The determinations were performed at specified wavelengths and the absorption values were recorded to calculate the conjugated diene and trien contents. The oxidative stability index (OSI) values were determined according to the Cd 12b-92 AOCS official method [17], by using a 743 Rancimat system (Methrom AG, Herisau, Switzerland). In the rancimat test, $3 \mathrm{~g}$ of oil was weighed into the reaction vessel placed into the heating block kept at $120^{\circ} \mathrm{C}$, air flow was set at $20 \mathrm{~L} \cdot \mathrm{h}^{-1}$. Volatile secondary oxidation compounds (short-chain acids, epoxides, aldehydes, and ketones) released during the heating process were collected in a receiving flask filled with $60 \mathrm{~mL}$ ultra-pure water, and then the conductivity of this water was measured and recorded. The induction times were automatically determined as the inflection point of the generated plot of conductivity $\left(\mu \mathrm{S} . \mathrm{cm}^{-1}\right)$ of the ultra-pure water versus time.

\subsection{RP-HPLC/DAD Analysis of Triglycerides}

Triglyceride profiles of cold pressed PSOs were determined by reverse-phase high performance liquid chromatography (RP-HPLC) technique according to the Ce 5b-89 AOCS official method [17]. Agilent 1200 series HPLC system (Agilent Technologies Inc., USA) was equipped with a G4214A model diodearray detector and ACE- $5 \mathrm{C} 18$ column $(250 \times 4 \mathrm{~mm}$ i.d., $5 \mu \mathrm{m})$ system at $30^{\circ} \mathrm{C} .5 \mu \mathrm{L}$ of the samples was injected and a mixture of acetone: acetonitrile $(50: 50, \mathrm{v} / \mathrm{v})$ was used as a mobile phase under isocratic conditions with a $1.5 \mathrm{~mL} \cdot \mathrm{min}^{-1}$ flow rate. Triglycerides were detected at wavelength of $205 \mathrm{~nm}$ and identified based upon comparison of their retention times with those of pure triglyceride standards, according to the equivalent carbon number $(\mathrm{ECN})$.

\subsection{UHPLC-MS/MS Analysis of Pesticide Residue}

The extraction procedure for pesticide residue analyses was carried out according to the original QuEChERS method (AOAC Official Method 2007.01) [18]. The UHPLC-MS/MS method parameters were optimized and validated onto our analysis system, based on QuEChERS method.

Extraction procedure: In brief, $15 \mathrm{~g}$ oil sample was weighed into a $50 \mathrm{~mL}$ fluoroethylenepropylene centrifugation tube. $15 \mathrm{~mL}$ of $1 \%$ acetic acid (HOAc) in $\mathrm{MeCN}, 6 \mathrm{~g}$ anhydrous $\mathrm{MgSO}_{4}$ and $1.5 \mathrm{~g} \mathrm{NaOAc}$ were added to a centrifuge tube. Then, the tubes were shaken vigorously for $1 \mathrm{~min}$ by hand; and centrifuged at $4000 \mathrm{rpm}$ for $5 \mathrm{~min} .4 \mathrm{~mL}$ of the supernatant was then transferred to centrifuge tube and $1.2 \mathrm{~g}$ anhydrous $\mathrm{MgSO}_{4} / 0.4 \mathrm{~g}$ primary secondary amine (PSA) sorbent were added. The mixture was centrifuged again for $5 \mathrm{~min}(4000 \mathrm{rpm})$. The extracts were put into auto-sampler vials for analysis by UHPLC-MS/MS to identify and determine a wide range of pesticide residues.

UHPLC-MS/MS method parameters: The chromatographic analyses were performed on Thermo Quantum AccMax UHPLC-MS/MS (Thermo, San Jose, CA, USA) system coupled to triple quadrupole analyzeroperated in the ESI positive mode. For the chromatographic separation, a Hypersil Gold $\mathrm{C}_{18}$ reversed phase column $(50 \times 2.1 \mathrm{~mm} ; 1.9 \mu \mathrm{m})$ was used. The parameters of the UHPLC-MS/MS system were as follows: column temperature, $25^{\circ} \mathrm{C}$; injection volume, $3 \mu \mathrm{L}$; flow rate, $300 \mu \mathrm{L} \cdot \mathrm{min}^{-1}$; eluent A: methanol; eluent B: $5 \mathrm{mM}$ formic acid in water. The chromatographic gradient program started from $25 \%$ eluent A, then went up linearly to $90 \% \mathrm{~A}$ in $5 \mathrm{~min}$, held this composition for $25 \mathrm{~min}$. Nitrogen was applied in the ion source gas at $12 \mathrm{~L} \cdot \mathrm{min}^{-1}$ and ion source temperature at $350^{\circ} \mathrm{C}$. The $\mathrm{N}_{2}$ supply pressure for the instrument was $40 \mathrm{psi}$, and the final MS/MS conditions included: $\mathrm{MS}_{1} / \mathrm{MS}_{2}, 100^{\circ} \mathrm{C} / 100^{\circ} \mathrm{C} ; 400$ 
V; 2.3 Torr- $8.79 \times 10^{-6}$ Torr. Data acquisition and processing was carried out with the Thermo LC Quan software.

Method validation: The validation of method was carried out in accordance with ISO/IEC 17025 [19] and considering European guidelines [14] in relation to selectivity, linearity, recovery, repeatability, within laboratory reproducibility, limits of detection (LOD) and quantification (LOQ).

The validation experiments were performed on five days $(n=5)$ and recovery studies were performed at 3 different mass fraction levels. The selectivity of proposed method was calculated by analysing blank pumpkin seed oils certified organic and checking for the lack of snooping peaks in the retention time section of analytes. The target analytes were differentiated from potential co-eluting matrix interferences by comparing the relative intensity of the ratio between quantifying and qualifying multiple reaction monitoring mode (MRM) transition obtained in the sample to that related to pure calibration standards. The calibration was carried out by injecting the set of pesticide standards in triplicate, on each day $(n=5)$. Calibration curves were created by plotting the peak area versus the mass fraction ratios for all pesticides. At five different target mass fraction levels in the range; $10-250 \mu \mathrm{g}^{\mathrm{kg}}{ }^{-1}$ for carbaryl, chlorpyrifos, methidathion and simazine; $10-500 \mu \mathrm{g} \cdot \mathrm{kg}^{-1}$ for dimethoate and diuron; $1-50 \mu \mathrm{g} \cdot \mathrm{kg}^{-1}$ for omethoate, phosmet and malathion. The values were selected taking into account both the UHPLCMS/MS method sensitivity and different maximum residue limits for each pesticide. Information about the regulation of pesticides was obtained from Codex Alimentarius and EU pesticide database [7, 20]. The linearity of each calibration curve was estimated by the residual plots and calculation of the correlation coefficients. To calculate the LOD and LOQ of proposed method, on each of the five days of the validation three matrix blanks were spiked at a level related to the lowest point of the calibration curve. The samples were processed as described and injected to the system in triplicate. LOD and LOQ values were calculated as 3 and 10 times, and the standard deviation of the signal declared in mass units. To determine the repeatability of method and within-laboratory intermediate precision; five blank samples were spiked at a mass fraction point corresponding to the middle point of the calibration curves (100 $\mu \mathrm{g} \cdot \mathrm{kg}^{-1}$ for carbaryl, chlorpyrifos, methidathion and simazine; $200 \mu \mathrm{g} \cdot \mathrm{kg}^{-1}$ for dimethoate and diuron; $20 \mu \mathrm{g} . \mathrm{kg}^{-1}$ for omethoate, phosmet and malathion), and injected in triplicate. The same procedure was repeated for five days. The repeatability and within-laboratory intermediate precision were estimated by using the obtained results and the single-factor analysis of variance, ANOVA. The recovery values were estimated by spiking at three different mass fraction levels on five samples each and calculated by comparing both the measured fractions and theoretical. The sum of spiked mass fractions for each pesticide was considered as the theoretical, and the measured fraction was the sum of the calculated mass fractions.

\subsection{UHPLC-MS/MS Analysis of Aflatoxin Contamination}

The extraction procedure for aflatoxin analyses was performed according to the Yang et al. (2011) [20]. The UHPLC-MS/MS analyses were carried out according to the proposed method by Shi et al. (2011) [21].

Extraction procedure: $5 \mathrm{~g}$ oil samples were accurately weighed and $5 \mathrm{~g} \mathrm{NaCl}$ and methanol/ultra-pure water $(7: 3, \mathrm{v} / \mathrm{v})$ were added to give a final volume of $20 \mathrm{~mL}$ in centrifuge tube. The mixtures were shaken vigorously for $2 \mathrm{~min}$ by a mechanical shaker. Then, $15 \mathrm{~mL}$ extract was collected and diluted with $30 \mathrm{~mL}$ ultra-pure water and the mixture was re-filtered before SPE purification. The AflaTestP ${ }^{\circledR}$ immuno-affinity SPE cartridge columns were connected to the Vac-Elut-20 manifold system (Agilent Technologies Inc., USA). Then, $15 \mathrm{~mL}$ of the sample extract was eluted through the immuno-affinity SPE cartridge at a rate of $6 \mathrm{~mL} \cdot \mathrm{min}^{-1}$. The cartridge was cleaned with $10 \mathrm{~mL}$ ultra-pure water. Aflatoxins were eluted with $1 \mathrm{~mL}$ methanol and the mobile phase was kept in contact with the cartridge for $2 \mathrm{~min}$ to guarantee complete elution. Then, eluent were dried and diluted with $1 \mathrm{~mL}$ of mixture of methanol: water $(98: 2, \mathrm{v} / \mathrm{v})$ before UHPLC-MS/MS analysis. 
UHPLC-MS/MS Method Parameters: The UHPLC-MS/MS system used for analysis was a Thermo Quantum AccMax UHPLC-MS/MS (Thermo, San Jose, CA, USA) in combination with a coupled to triple quadrupole mass spectrometer. A Hypersil Gold $\mathrm{C}_{18}$ reversed phase column $(50 \times 2.1 \mathrm{~mm} ; 1.9 \mu \mathrm{m})$ was used as a chromatographic column. The mobile phase system consisted of (A) ultra-pure water and (B) methanol at a flow rate of $0.4 \mathrm{~mL} \cdot \mathrm{min}^{-1}$. The mobile phase programme varied linearly as follows: $0.00 \mathrm{~min}, 2 \% \mathrm{~B} ; 1.45 \mathrm{~min}, 80 \% \mathrm{~B} ; 2.30 \mathrm{~min}, 90 \% \mathrm{~B} ; 3.15 \mathrm{~min}, 98 \% \mathrm{~B} ; 4.45 \mathrm{~min}, 2 \% \mathrm{~B}$ and held this composition for $8 \mathrm{~min}$ [21]. The injection volume was $20 \mu \mathrm{L}$ and the column temperature was maintained at $25^{\circ} \mathrm{C}$. The parameters used for the mass spectrometer with ESI positive mode were set as follows: spray voltage $3.5 \mathrm{kV}$, sheath gas pressure 50 arbitrary units, auxiliary gas pressure 20 arbitrary units, capillary temperature $250^{\circ} \mathrm{C}$, Collision gas pressure $1.5 \mathrm{mT}$ orr. Data acquisition and processing was carried out with the Thermo LC Quan software.

\subsection{Statistical Analysis}

All extractions and analyses were conducted in triplicates. Data were expressed as the mean \pm standard deviation (SD). Results were analyzed with one-way analysis of variance, ANOVA and differences between individual means were deemed to be significant at $P<0.05$. All statistical analyses were performed by means of Excel (Microsoft, 2007) and OriginPro8 (OriginLab, USA) databases.

\section{RESULTS AND DISCUSSION}

\subsection{Composition of Pumpkin Seeds (Cucurbita pepo L.) from Central Anatolia Region of Turkey}

The moisture and oil contents of naked pumpkin seed samples (Cucurbita pepo L.) were analyzed before the screw-pressing process. The moisture contents of seeds were quite low and detected as $4.1 \%$ for Celtik, 3.9\% for Cumra, $4.2 \%$ for Iceri Cumra, and 3.8\% for Polatl pumpkin seeds. Non-significant differences in moisture content were observed among the pumpkin seeds from the four different regions. Higher moisture content could lead to oily seed spoilage through rising microbial and enzymatic actions. Due to this reason, these pumpkin seed samples could be stored for a long time without any decomposition [22]. The oil contents of pumpkin seeds, as important nutritional factors, are calculated as the percent from the total amount of oil from a known amount of seeds. With screw-pressing process, the oil contents were detected as $45.2 \%$ for Celtik, $43.7 \%$ for Cumra, $47.4 \%$ for Iceri Cumra, and $42.8 \%$ for Polatli pumpkin seeds. The results of oil contents obtained from our analysis were lower than $60 \%$ value that reported for the European variety of Cucurbita pepo L [23]. However, the results of our research are in good agreement with some reported studies. Vasconcellos et al. (1981) [24], Idouraine et al. (2009) [25], Jafari et al. (2012) [9], and Young Kim et al. (2012) [26]reported that the oil contents of Cucurbita pepo L. cultivars were determined between $21.0-43.0 \%, 34.5-43.6 \%, 36.9-47.8 \%$, and 43.99-52.43\% values, respectively. These researches also declared that varieties in the oil contents could be attributed to the differences in genetic diversity, climate conditions, ripening stage and extraction methods. These oil contents are higher than several commercial oilseeds, so studied pumpkin seed could be introduced as a novel source of vegetable oil for industry applications [9].

\subsection{Physicochemical Characteristics aed Oxidative Stability of Cold Pressed Pumpkin Seed Oils}

The results of basic physicochemical characteristics and oxidative stabilities of four naked cold pressed PSOs are presented in Table 1. The chemical properties; peroxide value (PV), iodine value (IV), free fatty acid (FFA), saponification number (SN), unsaponified matter (USM), specific extinctions at 232 $\mathrm{nm}\left(\mathrm{K}_{232}\right)$ and $270 \mathrm{~nm}\left(\mathrm{~K}_{270}\right)$ were determined to characterize the cold pressed PSOs.

Peroxide value has been commonly used as one of the most important parameters to determine the quality and oxidative stability of edible oils [27]. The quite low PVs were detected as $3.10 \pm 0.10$ meq $\mathrm{O}_{2} / \mathrm{kg}$ oil for Celtik, $3.40 \pm 0.10$ meq $\mathrm{O}_{2} / \mathrm{kg}$ oil for Cumra, $3.16 \pm 0.05 \mathrm{meq} \mathrm{O}_{2} / \mathrm{kg}$ oil for Iceri Cumra, and 
$3.60 \pm 0.50 \mathrm{meq} \mathrm{O}_{2} / \mathrm{kg}$ oil for Polatl $\mathrm{PSOs}$, respectively. Even though PSOs were crude, none of the studied oils exceeded the limit of 15 meq $\mathrm{O}_{2} / \mathrm{kg}$ oil offered by the Codex standard cold pressed and virgin edible oils [7]. The FFA contents, which indicate enzymatic activity, were detected as $0.270 \pm 0.010 \%$ oleic acid, $0.260 \pm 0.005 \%$ oleic acid, $0.270 \pm 0.010 \%$ oleic acid, and $0.260 \pm 0.005 \%$ oleic acid for Celtik, Cumra, Iceri Cumra and Polatlı PSOs, respectively. The FFA contents of all the studied cold pressed oils were also well within the Codex limit of up to $2 \%$ oleic acid of virgin and cold pressed oils $[7,27]$. Another important parameter saponification number, indicating relatively molecular weight of fatty acids esterified in triacylglycerol structure, was determined. The saponification numbers were in the range of $201.91 \pm 1.49$ to $290.78 \pm 1.26 \mathrm{mg} \mathrm{KOH} / \mathrm{g}$ oil. The highest SV of $290.78 \pm 1.26 \mathrm{mg} \mathrm{KOH} / \mathrm{g}$ oil was detected for Iceri Cumra PSO, while the lowest value of $201.91 \pm 1.49 \mathrm{mg} \mathrm{KOH} / \mathrm{g}$ oil was detected for Cumra PSO. The saponification numbers in the present study were in good agreement with previous reports for cold pressed PSOs [9, 28]. The content of unsaponified matters (USM) provides useful data for identification of adulterants, detected as $0.84 \pm 0.01 \mathrm{~g} / \mathrm{kg}$ oil for Celtik, $0.65 \pm 0.01 \mathrm{~g} / \mathrm{kg}$ oil for Cumra, $0.70 \pm 0.02 \mathrm{~g} / \mathrm{kg}$ oil for Iceri Cumra, and $0.60 \pm 0.03 \mathrm{~g} / \mathrm{kg}$ oil for Polatl1 PSOs. Since waxes, hydrocarbons, and valuable bioactive compounds such as sterols, tocochromanols, essensial fatty acids and vitamins considered as USM, determination of USM content in cold pressed oils is much significant [22]. The other important oil quality parameter, iodine value (IV) is a measure of the average amount of unsaturation and defined as a number of centigrams of iodine absorbed per gram of oil [27]. The iodine values indicating a relatively high degree of unsaturation were detected as $117.09 \pm 0.50 \mathrm{~g} \mathrm{I}_{2} / 100 \mathrm{~g}$ oil for Celtik, $117.23 \pm 0.40 \mathrm{~g} \mathrm{I}_{2} / 100 \mathrm{~g}$ oil for Cumra, $117.29 \pm 0.50 \mathrm{~g} \mathrm{I}_{2} / 100 \mathrm{~g}$ oil for Iceri Cumra, and 117.09 $\pm 0.30 \mathrm{~g} \mathrm{I}_{2} / 100 \mathrm{~g}$ oil for Polatl PSOs. The obtained results indicate that, the cold pressed PSOs are intensely unsaturated and therefore responsible forthe oxidative degradation reactions.

Table 1. Physicochemical characteristics of the cold pressed pumpkin seed (Cucurbita pepo L.) oils cultivated in central Anatolia regions of Turkey

\begin{tabular}{|c|c|c|c|c|}
\hline \multirow[b]{2}{*}{ Physicochemical analysis } & \multicolumn{4}{|c|}{$\begin{array}{l}\text { characteristics of the cold-pressed pumpkin seed oils from central } \\
\text { Anatolia region of Turkey (Cucurbita pepo } L \text {.) }\end{array}$} \\
\hline & Celtik/Konya & Cumra/Konya & Iceri C./Konya & Polatlı/Ankara \\
\hline peroxide value, (meq $\mathrm{O}_{2} / \mathrm{kg}$ oil) & $3.10 \pm 0.10$ & $3.40 \pm 0.10$ & $3.16 \pm 0.05$ & $3.60 \pm 0.50$ \\
\hline iodine value, $\mathrm{IV},\left(\mathrm{g} \mathrm{I}_{2} / 100 \mathrm{~g}\right.$ oil $)$ & $117.09 \pm 0.50$ & $117.23 \pm 0.40$ & $117.29 \pm 0.50$ & $117.09 \pm 0.30$ \\
\hline free fatty acid, FFA, (\% oleic acid) & $0.270 \pm 0.010$ & $0.260 \pm 0.005$ & $0.270 \pm 0.010$ & $0.260 \pm 0.005$ \\
\hline $\begin{array}{l}\text { saponification value, } \mathrm{SV}(\mathrm{mg} \\
\mathrm{KOH} / \mathrm{g} \text { oil) }\end{array}$ & $235.14 \pm 1.00$ & $201.91 \pm 1.49$ & $290.78 \pm 1.26$ & $290.68 \pm 1.09$ \\
\hline unsaponified matter, (g/ kg oil) & $0.84 \pm 0.01$ & $0.65 \pm 0.01$ & $0.70 \pm 0.02$ & $0.60 \pm 0.03$ \\
\hline specific extinction at $232 \mathrm{~nm}$ & $4.10 \pm 0.02$ & $3.59 \pm 0.01$ & $3.59 \pm 0.01$ & $4.02 \pm 0.01$ \\
\hline specific extinction at $270 \mathrm{~nm}$ & $2.15 \pm 0.01$ & $2.07 \pm 0.01$ & $2.07 \pm 0.02$ & $2.41 \pm 0.02$ \\
\hline$R$-value, $\mathrm{K}_{232} / \mathrm{K}_{270}$ & 1.91 & 1.73 & 1.73 & 1.67 \\
\hline $\begin{array}{l}\text { oxidative stability index, OSI, h } \\
\left(120^{\circ} \mathrm{C}, 20 \mathrm{~L} / \mathrm{h}\right)\end{array}$ & $7.52 \pm 0.20$ & $7.71 \pm 0.20$ & $6.46 \pm 0.10$ & $6.58 \pm 0.10$ \\
\hline refractive index, $\mathrm{RI},\left(25^{\circ} \mathrm{C}\right)$ & $1.480 \pm 0.050$ & $1.475 \pm 0.050$ & $1.479 \pm 0.050$ & $1.477 \pm 0.050$ \\
\hline viscosity, $40^{\circ} \mathrm{C}, \mathrm{mm}^{2} \cdot \mathrm{s}^{-1}$ & $35.49 \pm 0.10$ & $35.21 \pm 0.20$ & $35.42 \pm 0.10$ & $35.51 \pm 0.30$ \\
\hline color & $35 \mathrm{Y}+1.6 \mathrm{R}$ & $34 \mathrm{Y}+1.4 \mathrm{R}$ & $37 \mathrm{Y}+1.9 \mathrm{R}$ & $35 \mathrm{Y}+1.5 \mathrm{R}$ \\
\hline
\end{tabular}

Results are reported as means \pm SD of three replicate analyses $(n=3)$

The specific extinction at wavelengths of 232 and $270 \mathrm{~nm}$ and $R$-values $\left(\mathrm{K}_{232} / \mathrm{K}_{270}\right)$ of studied oils are also presented in Table $1 . \mathrm{K}_{270}$ and $\mathrm{K}_{232}$ indices are used to give information on the quality of oil and content of primary and secondary oxidation products [29]. The contents of conjugated dien and trien of seed oils were detected by measuring the specific extinction coefficients at $K_{232}$ and $K_{270}$, respectively. The $R$-values $\left(\mathrm{K}_{232} / \mathrm{K}_{270}\right)$ were determined as 1.91 for Celtik, for 1.73 Cumra, 1.73 for Iceri Cumra, and 1.67 for Polatl1 PSOs. Thus, the $R$-values determined for cold pressed PSOs, were considerably lower 
than the 10-15 for natural oils, and3 for refined oils, recommended by the codex standard for edible fats and oils [7]. The oxidative stability index (OSI) as an important criterion for quality control with respect to the stability and shelf life of oils [30].It wasdetected by rancimat measurements at $120^{\circ} \mathrm{C}$ with air flow of $20 \mathrm{~L}^{-1} \mathrm{~h}^{-1}$. The oxidative stabilities of cold pressed PSOs, expressed by the induction period (IP), were detected as $7.52 \pm 0.20 \mathrm{~h}$ for Celtik, $7.71 \pm 0.20 \mathrm{~h}$ for Cumra, $6.46 \pm 0.10 \mathrm{~h}$ for Iceri Cumra, and $6.58 \pm 0.10 \mathrm{~h}$ for Polatl 1 PSOs. Therefore, Fruhwirth and Hermetter (2008) suggested the antioxidant capacity of seed oil as a novel and significant criterion for quality-control with regard to the oxidative stability index and shelf life [31].

The physical properties; refractive index (RI), viscosity, and color values were also determined to characterize the cold pressed PSOs (Table 1). RI value of oils depends on their molecular weight, chain length of fatty acids, degree of unsaturation, and conjugation, so the degree of difference of characteristic oil from its real values may be a sign of its purity. In the study, RI values were determined as 1.480 \pm 0.050 for Celtik, $1.475 \pm 0.050$ for Cumra, $1.479 \pm 0.050$ for Iceri Cumra, and $1.477 \pm 0.050$ for Polatl region PSOs. Previous studies on PSOs from different origins, also reported similar RI values with our data $[6,12]$. The viscosity values obtained in our study were also similar to the findings of Andjelkovic et al. (2010) [12]. The viscosity values were measured as $35.49 \pm 0.10 \mathrm{~mm}^{2} \cdot \mathrm{s}^{-1}$ for Celtik, $35.21 \pm 0.20$ $\mathrm{mm}^{2} . \mathrm{s}^{-1}$ for Cumra, $35.42 \pm 0.10 \mathrm{~mm}^{2} . \mathrm{s}^{-1}$ for Iceri Cumra, and $35.51 \pm 0.30 \mathrm{~mm}^{2} . \mathrm{s}^{-1}$ for Polatl PSOs. As is known, the color of a vegetable oil is one of the most important characteristic affecting its preference by consumers and for determining the acceptance of edible oil. This characteristic is generally attributed to the amount of pigments, carotenoids, and phenolic pigments and also morphological factors. The color values presented in the Lovibond tintometer scale are expressed in terms of Lovibond Red (R) and Yellow (Y) units. All PSO samples weredark in color and measured as $35 \mathrm{Y}+1.6 \mathrm{R}$ value, $34 \mathrm{Y}+1.4$ $\mathrm{R}$ value, $37 \mathrm{Y}+1.9 \mathrm{R}$ value, and $35 \mathrm{Y}+1.5 \mathrm{R}$ value for Celtik, Cumra, Iceri Cumra and Polatli PSOs, respectively. As expected, the obtained color values were also in good agreement with Andjelkovic et al. (2010) [12]. Thus, there was a non-significant difference between the PSO samples from the four different regions, in terms of physicochemical characteristics. The results showed that the studied PSOs harvested in central Anatolia regions are high quality and stable cold pressed oils. Thus, the results proved that these cold pressed oils could be stored for a long time without any additional purification process.

\subsection{Triglyceride Profiling by RP-HPLC/DAD Technique}

In the study, the triglyceride analyses were performed according to the AOCS Ce5b-89 official method for triglyceride profiling in vegetable oils [17]. The results of triglyceride analysis are given in Table 2 and the chromatogram of Cumra cold pressed PSO is presented in Figure 1.

As can be seen from Table 2., the determined triglyceride isomers with different ECNs were; linoleinodilinolenin (LLnLn; 38:8), dilinoleinolinolenin (LLLn; 40:7), trilinolein (LLL; 42:6), oleolinoleolinolenin (OLLn; 42:6), palmitolinoleolinolenin (PLLn; 42:5), oleodilinolein (OLL; 44:5), linoleninopalmitooleoin (LnPO; 42:4), dioleolinolein (OOL; 46:4), palmitooleolinolein (POL; 46:3), dipalmitolinolein (PPL; 46:7), triolein (OOO; 48:3), stearooleolinolein (StOL; 48:3), and palmitolinoleostearin (PLSt; 48:2) (ECN: number of DBs). The percentages of main triglyceride isomer, OLL were detected as $23.703 \pm 0.013 \%, 23.895 \pm 0.018 \%, 23.155 \pm 0.017 \%$ and $24.022 \pm 0.016 \%$ for Celtik, Cumra, Iceri Cumra and Polatlı PSOs, respectively. Cold pressed PSOs have mainly triglycerides with equivalent chain numbers of 38, 40, 42, 44, 46 and 48. The major triglycerides with ECN of 42 values were detected as $33.98 \%$ for Celtik, $30.97 \%$ for Cumra, $36.54 \%$ for Iceri Cumra, and $35.65 \%$ for Polatl1 PSOs. The triglycerides with ECN of 44 values were detected as $23.70 \%$ for Celtik, $23.90 \%$ for Cumra, $23.16 \%$ for Iceri Cumra, and $24.02 \%$ for Polatl1 PSOs. The triglyceride analysis results are in good agreement with previous studies for PSOs. Butinar et al. (2010) and Nederal et al. (2012) reported that OLL was the dominant triacylglycerol in PSOs obtained, followed by LLL, LOO and PLO isomers $[6,32]$. 
Arslan et al. / Anadolu Univ. J. of Sci. and Technology A-Appl. Sci. and Eng. 18 (2) - 2017

Table 2. Triglyceride profile of the cold pressed pumpkin seed (Cucurbita pepo L.) oils cultivated in central Anatolia regions of Turkey

\begin{tabular}{|c|c|c|c|c|}
\hline \multirow[b]{2}{*}{ TG molecules } & \multicolumn{4}{|c|}{$\begin{array}{l}\text { Triglyceride analysis results of cold-pressed pumpkin seed oils from central Anatolia } \\
\text { region of Turkey (Cucurbita pepo } L \text {.) }\end{array}$} \\
\hline & Celtik/Konya & Cumra/Konya & Iceri Cumra/Konya & Polatlı/Ankara \\
\hline LLnLn & $0.158 \pm 0.001$ & $0.187 \pm 0.001$ & $0.255 \pm 0.001$ & $0.213 \pm 0.001$ \\
\hline LLLn & $0.605 \pm 0.002$ & $0.640 \pm 0.003$ & $0.646 \pm 0.001$ & $0.656 \pm 0.002$ \\
\hline LLL & $18.168 \pm 0.012$ & $19.553 \pm 0.014$ & $16.020 \pm 0.10$ & $19.269 \pm 0.013$ \\
\hline OLLn & $0.168 \pm 0.001$ & $0.193 \pm 0.002$ & $0.161 \pm 0.003$ & $0.164 \pm 0.001$ \\
\hline PLLn & $0.319 \pm 0.001$ & $0.313 \pm 0.001$ & $0.239 \pm 0.001$ & $0.289 \pm 0.001$ \\
\hline OLL & $23.703 \pm 0.013$ & $23.895 \pm 0.018$ & $23.155 \pm 0.017$ & $24.022 \pm 0.016$ \\
\hline LnPO & $15.321 \pm 0.011$ & $16.483 \pm 0.010$ & $14.552 \pm 0.014$ & $15.926 \pm 0.012$ \\
\hline OOL & $13.415 \pm 0.015$ & $11.824 \pm 0.012$ & $15.377 \pm 0.011$ & $12.411 \pm 0.011$ \\
\hline POL & $16.078 \pm 0.012$ & $15.842 \pm 0.011$ & $16.088 \pm 0.015$ & $15.537 \pm 0.013$ \\
\hline PPL & $2.077 \pm 0.004$ & $2.277 \pm 0.007$ & $2.281 \pm 0.003$ & $2.273 \pm 0.008$ \\
\hline OOO & $1.641 \pm 0.002$ & $1.287 \pm 0.003$ & $2.290 \pm 0.005$ & $1.431 \pm 0.002$ \\
\hline StOL & $6.390 \pm 0.006$ & $5.587 \pm 0.008$ & $6.857 \pm 0.009$ & $5.726 \pm 0.004$ \\
\hline PLSt & $1.955 \pm 0.003$ & $1.914 \pm 0.002$ & $2.078 \pm 0.004$ & $2.076 \pm 0.006$ \\
\hline
\end{tabular}

P; palmitic acid, St; stearic acid, O;oleic acid, L;linoleic acid, Ln; linolenic acid

Values are reported as means \pm SD of three replicate analyses $(n=3)$

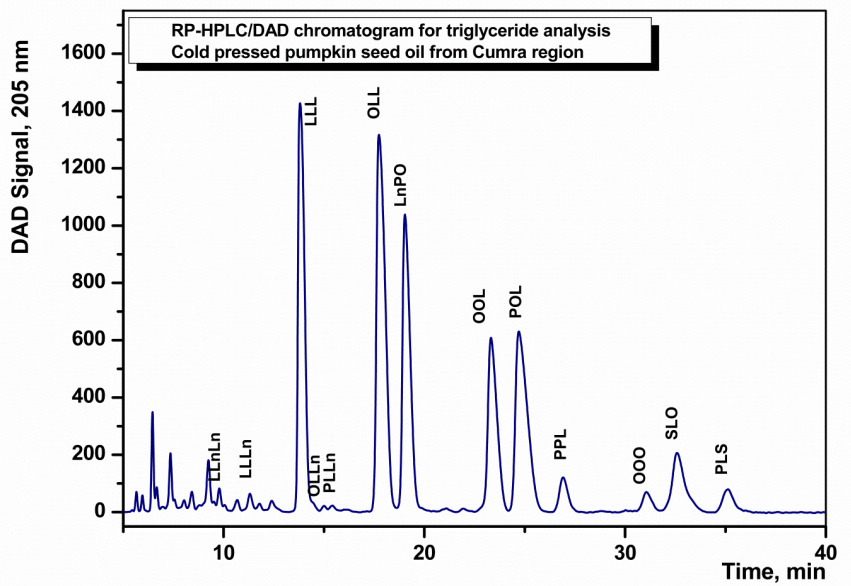

Figure 1. RP-HPLC/DAD chromatogram of cold pressed pumpkin seed oil from Cumra region for triglyceride analysis

\subsection{Pesticide Residue and Aflatoxin Contamination Analyses by UHPLC-MS/MS}

Due to common use of pesticides in cultivation, their residues in foodstuffs are practically unavoidable. Residues of pesticides, which were used in the past for plant/crop protection, in foods are mainly related to the environment, into which these chemicals are brought chiefly by human activities [11]. A sensitive, accurate and simple UHPLC-MS/MS method for the determination of 9 selected pesticides in PSOs, has been developed and validated. The procedure is based on sample extraction by the use of a QuEChERS AOAC-2007.01official method extraction [18], and following clean-up of the extract with PSA. The LC-MS/MS conditions of QuEChERS were also used with some modifications. The studied pesticide standards were separated on a Hypersil Gold $\mathrm{C}_{18}$ reversed phase column $(50 \times 2.1 \mathrm{~mm} ; 1.9 \mu \mathrm{m})$ using gradient elution with methanol-water $/ 5 \mathrm{mM}$ formic acid in mobile phase, and finally identified and quantified by triple quadrupole mass spectrometry in the multiple reaction monitoring mode (MRM). In literature, different $\mathrm{C}_{18}$ analytical columns were reported using different aqueous-organic mobile phase 
gradients, with either acetonitrile or methanol with $0.1 \%(\mathrm{v} / \mathrm{v})$ of formic acid. When comparing aqueousmethanol versus aqueous-acetonitrile mobile phase systems, better response and separation of the pesticides were also achieved with the methanol mobile phase gradient of QuEChERS official method $[18,33]$.

To achieve separation of studied pesticides and to maximize both sensitivity and precision of the method, the validation of proposed method was performed. The specificity of method was evaluated by the analysis of blank PSO samples. Pesticides were identified in the oil samples according to their $t_{R}$, and differentiated from any possible matrix interference by comparing the relative intensity of the ratio between quantification \& qualifying MRM transition obtained calibration standards, with that in relation to sample. The MRM ratios in samples were well within the acceptable levels for relative ion intensities as specified in the European guidelines [14], also no significant interferences from the PSO matrix were determined. The statistical parameters calculated from least-square regression are presented in Table 3. As can be seen from Table 3, the correlation coefficients (r) were determined higher than 0.99 value.

The LODs and LOQs of each analytes were calculated by spiking three blank PSO samples at the lowest level of the working range for each pesticide (Table 3). The LOD was theoretically estimated as 3 times the standard deviation, while the LOQ was estimated as 10 times the standard deviation obtained from analyses of independent samples at the lowest calibrated level. The LODs were confirmed experimentally, and the lowest spike mass fraction levels used in the recovery experiments were considered as validated the LOQs [14]. As given in Table 3, LOQs for studied pesticides were below the respective maximum residue limits. The precision of the method, estimated through the repeatability and within-laboratory intermediate precision is presented in Table 3.

The repeatability and intermediate precision values in the study stated as RSD were below $10 \%$. The recovery studies performed at three mass fraction levels of each individual pesticide and obtained results are given in Table 4. The obtained values for studied pesticides were higher than 95\%, with the exception of phosmet at the highest mass fraction level, for which recoveries of 93\% was obtained, with RSD ranging from $4.2 \%$. The obtained results present a good accuracy of the proposed methodology and so a suitability for the characterization of reference material.

Table 3. Working range and calibration equations of the selected pesticides $(n=5)$ and performance characteristics of the proposed UHPLC-MS/MS method

\begin{tabular}{|c|c|c|c|c|c|c|c|c|c|c|c|}
\hline \multirow[b]{3}{*}{ Pesticide } & \multirow[b]{3}{*}{ 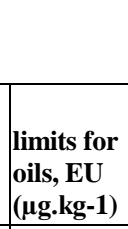 } & \multirow[b]{3}{*}{$\begin{array}{l}\text { retention } \\
\text { time (tR) }\end{array}$} & \multirow[b]{3}{*}{$\begin{array}{l}\mathrm{m} / \mathrm{z} \\
\text { parent }\end{array}$} & \multicolumn{2}{|c|}{$\begin{array}{l}\text { mass fraction } \\
\text { linear range }\end{array}$} & \multirow[b]{3}{*}{ calibration equation } & \multirow[b]{3}{*}{$\mathbf{r}$} & \multirow[b]{3}{*}{$\begin{array}{l}\text { regression } \\
\text { std. dev. }\end{array}$} & \multirow[b]{3}{*}{$\begin{array}{l}\text { LOD } \\
\left(\mu \mathrm{g} . \mathrm{kg}^{-1}\right)\end{array}$} & \multirow{2}{*}{\multicolumn{2}{|c|}{ LOQ }} \\
\hline & & & & \multirow[b]{2}{*}{\begin{tabular}{|l|} 
matrix \\
$(\mu \mathrm{g} . \mathrm{kg}-1)$
\end{tabular}} & \multirow[b]{2}{*}{$\begin{array}{l}\text { standard } \\
(\mu \mathrm{g} . \mathrm{kg}-1)\end{array}$} & & & & & & \\
\hline & & & & & & & & & & \begin{tabular}{|} 
estimated \\
$(\mu \mathrm{g} . \mathrm{kg}-1)$
\end{tabular} & $\begin{array}{l}\text { validated } \\
(\mu \mathrm{g} . \mathrm{kg}-1)\end{array}$ \\
\hline carbaryl & 50 & 10.46 & 202.2 & $10-500$ & $10-250$ & $y=16840 x+94918$ & 0.9953 & 579 & 3 & 10 & 10 \\
\hline chlorpyrifos & 50 & 14.05 & 351.9 & $10-500$ & $10-250$ & $y=16488 x+105464$ & 0.99832 & 338 & 2 & 10 & 10 \\
\hline dimethoate & 200 & 8.82 & 230.0 & $10-1000$ & $10-500$ & $y=8245 x+157856$ & 0.9993 & 110 & 5 & 10 & 30 \\
\hline diuron & 200 & 10.65 & 233.1 & $10-1000$ & $10-500$ & $\mathrm{y}=8350 \mathrm{x}+175798$ & 0.9979 & 192 & 8 & 10 & 30 \\
\hline malathion & 20 & 11.30 & 331.0 & $10-200$ & $1-50$ & $y=83468 x+156354$ & 0.9994 & 1008 & 0.5 & 10 & 20 \\
\hline methidathion & 50 & 11.26 & 303.0 & $10-500$ & $10-250$ & $y=16452 x+125259$ & 0.9962 & 506 & 1 & 10 & 20 \\
\hline omethoate & - & 4.68 & 214.1 & $10-200$ & $1-50$ & $\mathrm{y}=84107 \mathrm{x}+158154$ & 0.9986 & 1581 & 0.4 & 10 & 10 \\
\hline phosmet & - & 11.24 & 318.0 & $10-200$ & $1-50$ & $y=84269 x+171374$ & 0.9984 & 1680 & 0.7 & 10 & 15 \\
\hline simazine & 100 & 9.21 & 202.0 & $10-500$ & $10-250$ & $y=16573 x+118524$ & 0.9961 & 519 & 6 & 10 & 25 \\
\hline
\end{tabular}

r; correlation coefficient, LOD; limit of detection, LOQ; limit of quantification 
Arslan et al. / Anadolu Univ. J. of Sci. and Technology A-Appl. Sci. and Eng. 18 (2) - 2017

Table 4. Mean recovery and RSD $(n=5)$ values calculated for the studied pesticides spiked at three different concentration levels

\begin{tabular}{|c|c|c|c|c|c|c|c|c|c|}
\hline Pesticides & $\begin{array}{c}\text { spiked } \\
\left(\mu \mathrm{g} . \mathrm{kg}^{-1}\right)\end{array}$ & $\begin{array}{c}\text { recovery } \\
(\%)\end{array}$ & $\begin{array}{c}\text { RSD } \\
(\%)\end{array}$ & $\begin{array}{c}\text { spiked } \\
\left(\mu \mathrm{g} . \mathrm{kg}^{-1}\right)\end{array}$ & $\begin{array}{c}\text { recovery } \\
(\%)\end{array}$ & $\begin{array}{c}\text { RSD } \\
(\%)\end{array}$ & $\begin{array}{c}\text { spiked } \\
\left(\mu \mathrm{g} . \mathrm{kg}^{-1}\right)\end{array}$ & $\begin{array}{c}\text { recovery } \\
(\%)\end{array}$ & $\begin{array}{l}\text { RSD } \\
(\%)\end{array}$ \\
\hline carbaryl & 50 & 102 & 3.7 & 100 & 99 & 3.9 & 200 & 105 & 4.6 \\
\hline chlorpyrifos & 50 & 99 & 4.2 & 100 & 104 & 4.1 & 200 & 97 & 4.1 \\
\hline dimethoate & 100 & 97 & 5.1 & 200 & 98 & 6.1 & 400 & 99 & 6.3 \\
\hline diuron & 100 & 103 & 4.3 & 200 & 97 & 4.2 & 400 & 101 & 5.2 \\
\hline malathion & 10 & 102 & 4.1 & 20 & 106 & 5.1 & 40 & 97 & 5.3 \\
\hline methidathion & 50 & 98 & 5.3 & 100 & 95 & 5.2 & 200 & 101 & 4.7 \\
\hline omethoate & 10 & 99 & 3.9 & 20 & 98 & 4.8 & 40 & 97 & 4.9 \\
\hline phosmet & 10 & 96 & 5.3 & 20 & 93 & 4.2 & 40 & 98 & 3.2 \\
\hline simazine & 50 & 101 & 4.1 & 100 & 103 & 5.5 & 200 & 105 & 5.2 \\
\hline
\end{tabular}

The validated method was applied to the analysis of pumpkin seed oil samples. Among the studied pesticides, only chlorpyrifos pesticide residues were detected as $18.050 \pm 0.470 \mathrm{ppb}\left(\mu \mathrm{g} . \mathrm{kg}^{-1}\right)$ for Celtik PSO, $10.430 \pm 0.620 \mathrm{ppb}$ for Cumra PSO and $12.340 \pm 0.820 \mathrm{ppb}$ for Polatl1 PSO (Figure 2). For Iceri Cumra PSO sample, no pesticide residue was detected by using proposed method (Table 5). The contents of chlorpyrifos for studied oils were considerably under the limit value $\left(50 \mu \mathrm{g} \cdot \mathrm{kg}^{-1}\right)$ stated by official authorities for the quality assessment of edible oils [7, 14].

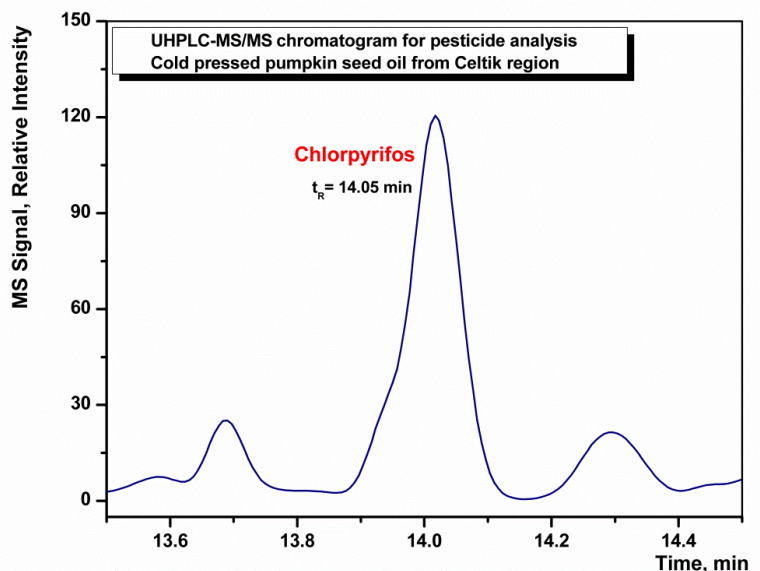

(a)

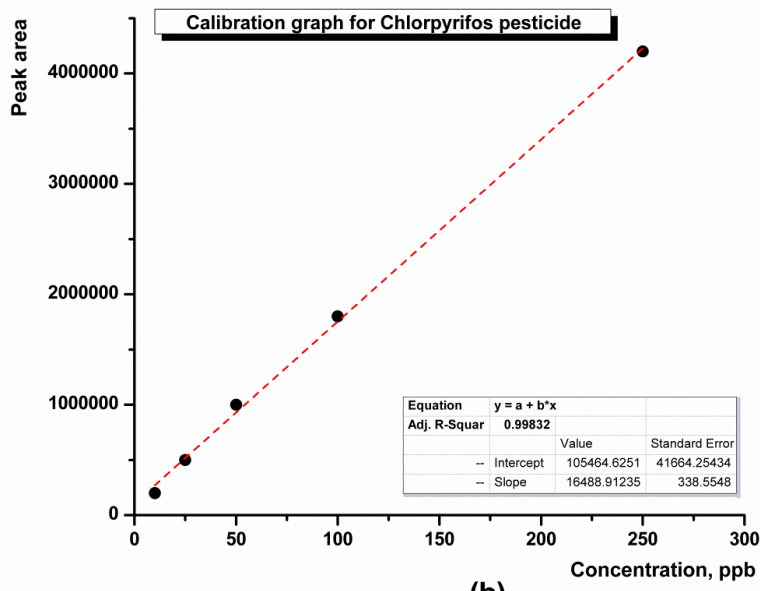

(b)

Figure 2. (a) UHPLC-MS/MS chromatogram of cold pressed pumpkin seed oil from Celtik region for pesticide analysis (b) calibration graph for chlorpyrifos pesticide

Table 5. Pesticide analysis results of cold-pressed pumpkin seed oils from central Anatolia region of Turkey (Cucurbita pepo L.)

\begin{tabular}{|c|c|c|c|c|}
\hline \multicolumn{5}{|c|}{$\begin{array}{c}\text { Pesticide analysis results of cold-pressed pumpkin seed oils from central Anatolia region of } \\
\text { Turkey (Cucurbita pepo L.) }\end{array}$} \\
\hline & Celtik/Konya & Cumra/Konya & Iceri Cumra/Konya & Polatlı/Ankara \\
\hline $\begin{array}{l}\text { content of chlorpyrifos } \\
\left(\mu \mathrm{g} . \mathrm{kg}^{-1}\right)\end{array}$ & $18.050 \pm 0.470$ & $10.430 \pm 0.620$ & nd & $12.340 \pm 0.820$ \\
\hline
\end{tabular}

Results are reported as means $\pm \mathrm{SD}$ of three replicate analyses $(n=3)$ 
The contaminations of aflatoxin were determined by the LC-MS/MS method described by Shi et al. (2011)[21]. The stock mix aflatoxin solutions were prepared in methanol and four aflatoxins were analyzed under electrospray ionization $\left(\mathrm{ESI}^{+}\right)$mode. The chromatogram of aflatoxin standards $\left(\mathrm{AF}-\mathrm{B}_{1}\right.$, AF- $B_{2}, A F-G_{1}$ and $A F-G_{2}$ ) is presented in Figure 3.

Aflatoxin standard concentrations of $1 \mu \mathrm{g} \cdot \mathrm{kg}^{-1}, 5 \mu \mathrm{g} \cdot \mathrm{kg}^{-1}, 10 \mu \mathrm{g} \cdot \mathrm{kg}^{-1}$ and $25 \mu \mathrm{g} \cdot \mathrm{kg}^{-1}$ in methanol, were used for calibration curves by using UHPLC-MS/MS system. The correlation coefficients (linear regressions) were obtained higher than 0.9900 for each aflatoxin standards. Aflatoxin $B_{1}, B_{2}, G_{1}$ and $G_{2}$ contaminations were not detected in any of studied pumpkin seed oil sample. The maximum acceptable level of aflatoxin in food materials has been regulated in many countries and the legal limits may vary from one country to another, depending on the degree of development and economic consideration. The food and drug administration (FDA) has set a maximum acceptable level of $20 \mu \mathrm{g} \cdot \mathrm{kg}^{-1}$ for total aflatoxin in all foods for human consumption [34]. Thus, the obtained data indicate that the cold pressed pumpkinseed oils from central Anatolia region of Turkey have high quality properties and physicochemical characteristics of edible oil and may be considered a good source of bioactive compounds. Also, the study is the first data on the presence of pesticides in cold pressed pumpkinseed oils.

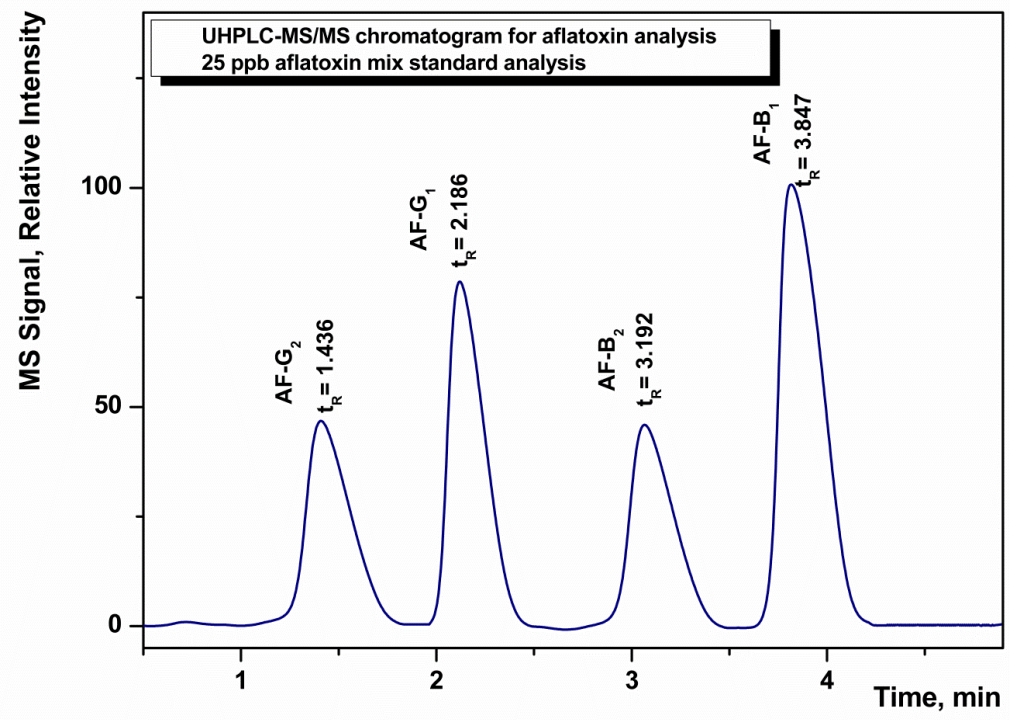

Figure 3. UHPLC-MS/MS chromatogram of aflatoxin mixture standard $\left(A F-G_{2}, A F-G_{1}, A F-B_{2}\right.$ and $\left.A F-B_{1}\right)$

\section{CONCLUSION}

Production of cold pressed pumpkin seed oils has been an important issue for edible oil industry and studied for different purposes. Cold pressed pumpkin seed oils are an extraordinary rich source of bioactive compounds. In this study, cold pressed pumpkin seed oils produced by screw-pressing the seeds, were characterised by determining their basic physicochemical characteristic and evaluating the contents of pesticide and aflatoxin contaminations. Physicochemical characteristic of the studied oils, cultivated in four different central Anatolia regions of Turkey, showed that the oils have high quality and potential to be used as nutrient rich edible oil. Besides, it was found that studied oils were wellaccepted cold pressed oils in terms of toxic pesticide and aflatoxin contaminations. Therefore, pumpkin seed oils can be utilized as functional ingredients for the development and formulation of new functional food products. Moreover, the results of the study are expected to increase the knowledge on the characteristics of edible pumpkin seed oils and provide as valuable contributions to the literature by this study. 


\section{ACKNOWLEDGEMENT}

The present study was supported by Karamanoğlu Mehmetbey University (Karaman, Turkey) Scientific Research Project Centre with 05-YL-15 and 14-M-16 project numbers. The research is also a part of master thesis entitled "Determination of active components in pumpkin seed oil by HPLC and GC-MS". Authors wish to thank K.M.U. Scientific Research Project Centre for the facilities provided.

\section{ABBREVIATIONS}

$\begin{array}{ll}\text { AF } & \text { aflatoxin } \\ \text { ANOVA } & \text { analysis of variance } \\ \text { AOCS } & \text { american oil chemical society } \\ \text { DAD } & \text { diode array detector } \\ \text { ECN } & \text { equivalent chain numbers } \\ \text { ESI } & \text { electrospray ionization } \\ \text { FDA } & \text { food and drug administration } \\ \text { FFA } & \text { free fatty acid } \\ \text { GAE } & \text { gallic acid equivalent } \\ \text { GC } & \text { gas chromatography } \\ \text { GC-MS } & \text { gas chromatography-mass spectroscopy } \\ \text { IV } & \text { iodine value } \\ \text { LC-MS/MS } & \text { liquid chromatography- mass spectroscopy/ mass spectroscopy } \\ \text { LLL } & \text { trilinolein } \\ \text { LLLn } & \text { dilinoleinolinolenin } \\ \text { LLnLn } & \text { linoleinodilinolenin } \\ \text { LnPO } & \text { linoleninopalmitooleoin } \\ \text { LOD } & \text { limit of detection } \\ \text { LOQ } & \text { limit of quantification } \\ \text { LU } & \text { lovibond unit } \\ \text { MRM } & \text { multiple reaction monitoring } \\ \text { MS } & \text { mass spectroscopy } \\ \text { NOP } & \text { national organic program } \\ \text { OLL } & \text { oleodilinolein } \\ \text { OLLn } & \text { oleolinoleolinolenin } \\ \text { OOL } & \text { dioleolinolein } \\ \text { OOO } & \text { triolein } \\ \text { OSI } & \text { oxidative stability index } \\ \text { PLLn } & \text { palmitolinoleolinolenin } \\ \text { PLSt } & \text { palmitolinoleostearin } \\ \text { POL } & \text { palmitooleolinolein } \\ \text { PPL } & \text { dipalmitolinolein } \\ \text { PSA } & \text { primary secondary amine } \\ \text { PSO } & \text { pumpkin seed oil } \\ \text { PV } & \text { refractive index } \\ \text { RI } & \text { reverse phase-high performance liquid chromatograph } \\ \text { RP-HPLC } & \text { a }\end{array}$


Arslan et al. / Anadolu Univ. J. of Sci. and Technology A-Appl. Sci. and Eng. 18 (2) - 2017

$\begin{array}{ll}\text { SM } & \text { saponified matters } \\ \text { SPE } & \text { solid phase extraction } \\ \text { StOL } & \text { stearooleolinolein } \\ \text { SV } & \text { saponification value } \\ \text { UHPLC } & \text { ultra fast high performance liquid chromatograph } \\ \text { UHPLC-MS/MS } & \begin{array}{l}\text { ultra fast high performance liquid chromatography-mass spectroscopy/ mass } \\ \text { spectroscopy } \\ \text { USM }\end{array} \\ \text { unsaponified matters }\end{array}$

\section{REFERENCES}

[1] Tadmor Y, Paris HS, Meir A. Dual role of the pigmentation gene B in affecting carotenoid and vitamin E content in squash (Cucurbita pepo) mesocarp. J Agric Food Chem 2005; 53: 9759-9763.

[2] Lim TK. Cucurbita pepo L. Edible Med. Non-Medicinal Plants. 2012; 3: 281-294.

[3] Haiyan Z, Bedgood DR, Bishop AG, Prenzler PD, Robards K. Endogenous biophenol, fatty acid and volatile profiles of selected oils. Food Chem 2007; 100: 1544-1551.

[4] Caili F, Huan S, Quanhong L. A review on pharmacological activities and utilization technologies of pumpkin. Plant Foods Hum Nutr 2006; 61:73-80.

[5] Rabrenovi BB, Dimi EB, Novakovi MM, Tešević VV, Basić ZN. The most important bioactive components of cold pressed oil from different pumpkin (Cucurbita pepo L.) seeds. LWT-Food Sci Technol 2014; 55, 521-527.

[6] Nederal S, Škevin D, Kraljić K, Obranović M, Papeša S, Bataljaku A. Chemical composition and oxidative stability of roasted and cold pressed pumpkin seed oils. J Am Oil Chem Soc 2012; 89, $1763-$ 1770.

[7] Codex Standard for Edible Fats and Oils not covered by Individual Standards (CODEX STAN 191981; Rev. 2 -1999).

[8] Boaduo NKK, Katerere D, Eloff JN, Naidoo V. Evaluation of six plant species used traditionally in the treatment and control of diabetes mellitus in South Africa using in vitro methods. Pharm Biol 2014; 52: 756-761.

[9] Jafari M, Goli SAH, Rahimmalek M. The chemical composition of the seeds of Iranian pumpkin cultivars and physicochemical characteristics of the oil extract. Eur J Lipid Sci Technol 2012; 114:161167.

[10] Hammer KA, Carson CF, Riley TV. Antimicrobial activity of essential oils and other plant extracts. J Appl Microbiol 1999; 86: 985-990.

[11] Yu L, Parry JWZK. In: Bailey’s Industrial Oil and Fat Products. (6th edn. Wiley, USA, 2005, pp. 250-252.

[12] Andjelkovic M, Van Camp J, Trawka A, Verhé R. Phenolic compounds and some quality parameters of pumpkin seed oil. Eur J Lipid Sci Technol 2010; 112: 208-217. 
[13] Murkovic M, Pfannhauser W. Stability of pumpkin seed oil. Eur J Lipid Sci Technol 2000; 102: 607-611.

[14] SANTE/EU/2007/3131, Method Validation and Quality Control Procedures for Pesticide Residues Analysis in food and feed. SANCO/10232/2006, http://crl-pesticides.eu/library/docs/allcrl/Aqc GuidanceSanco_2007_3131.pdf, accessed on 18.08.2016.

[15] ISO 665, Oilseed meals-determination of oil content-Part 1: Extraction method with hexane (or light petroleum). International Organization for Standardization, 2006; Geneva (ISO 665).

[16] ISO 734-1, Oilseeds-determination of moisture and volatile matter content. International Organization for Standardization, 2000; Geneva (ISO 734-1).

[17] Firestone, D. Official methods and recommended practices of the AOCS. American Oil Chemists' Society, 2009.

[18] AOAC International Official Method 2007.01, Pesticide Residues in Foods by Acetonitrile Extraction and Partitioning with Magnesium Sulfate. Off Methods Anal AOAC 2011; 90: 17 - 26.

[19] ISO/IEC 17025, General requirements for the competence of testing and calibration laboratories. International Organization for Standardization, 2005; Geneva (ISO/IEC 17025).

[20] Yang LX, Liu YP, Miao H, Dong B, Yang N, Chang F, Yang L, Sun J. Determination of aflatoxins in edible oil from markets in Hebei Province of China by liquid chromatography-tandem mass spectrometry. Food Addit Contam Part B-Surveillance 2011; 4: 244-247.

[21] Shi Y, Lafontaine C, Espourteille F. Detection of Mycotoxins in Corn Meal Extract Using Automated Online Sample Preparation with LC-MS/MS. https://tools.thermofisher.com/content/sfs/brochures/ AN63403_MycotoxinsTLX1_FINAL(2).pdf, Thermo Fisher Scientific Inc. Application Note: 523, 2011 accessed on 18.08.2016.

[22] Esuoso K, Lutz H, Kutubuddin M, Bayer E. Chemical composition and potential of some underutilized tropical biomass. I: Fluted pumpkin (Telfairia occidentalis). Food Chem 1998; 61: 487492.

[23] Murkovic M, Hillebrand A, Winkler J, Leitner E, Pfannbauser W. Variability of fatty acid content in pumpkin seeds (Cucurbita pepo L.). Z Lebensm Unters Forsch 1996; 203: 216-219.

[24] Vasconcellos JA, Bemis WP, Berry JM, Weber CW. The buffalo gourd, Cucurbita foetidissima HBK, as a source of edible oil. J Am Oil Chem Soc 1981; 9: 55-68.

[25] Idouraine A, Kohlhepp EA, Weber CW, Martinez-Tellez JJ. Nutrient Constituents from Eight Lines of Naked Seed Squash (Cucurbita pepo L.). J Agric Food Chem 1996; 44: 721-724.

[26] Young KM, Kim EJ, Kim YN, Choi CLB. Comparison of the chemical compositions and nutritive values of various pumpkin (Cucurbitaceae) species and parts. Nutr Res Pract 2012; 6: 21-27.

[27] Arslan FN, Sapcı AN, Duru F, Kara H. A study on monitoring of frying performance and oxidative stability of cottonseed and palm oil blends in comparison with original oils. Int J Food Prop 2016; doi: 10.1080/10942912.2016.1177544. 
[28] Tsaknis J, Lalas S, Lazos ES. Characterization of crude and purified pumpkin seed oil. Grasas Aceites 1997; 48: 267-272.

[29] Rezig L, Chouaibi M, Msaada K, Hamdi S. Chemical composition and profile characterisation of pumpkin (Cucurbita maxima) seed oil. Ind Crop Prod 2012; 37: 82-87.

[30] Naziri E, Mitić MN, Tsimidou MZ. Contribution of tocopherols and squalene to the oxidative stability of cold-pressed pumkin seed oil (Cucurbita pepo L.). Eur J Lipid Sci Technol 2016; 118: 898905.

[31] Fruhwirth GO, Hermetter A. Production technology and characteristics of Styrian pumpkin seed oil. Eur J Lipid Sci Technol 2008; 110: 637-644.

[32] Butinar B, Bucar-Miklavcic M, Valencic V, Raspor P. Stereospecific analysis of triacylglycerols as a useful means to evaluate genuineness of pumpkin seed oils: Lesson from virgin olive oil analyses. J Agric Food Chem 2010; 58: 5227-5234.

[33] Kmeller B, Pareja L, Ferrer C, Fodor P, Fernández-Alba AR. Study of the effects of operational parameters on multiresidue pesticide analysis by LC-MS/MS. Talanta 2011; 84: 262-273.

[34] Ruiqian L, Qian Y, Thanaboripat D, Thansukon P. Biocontrol of Aspergillus flavus and aflatoxin production. Iran J Environ Heal Sci Eng 2004; 4: 1685-2044. 